\title{
Consciência fonológica e língua estrangeira: um estudo acerca da aprendizagem de espanhol por falantes brasileiros
}

\author{
Phonological consciousness and foreign languages: a study on the \\ learning of Spanish by Brazilian speakers
}

Fabiana Soares da Silva ${ }^{1}$, Susiele Machry da Silva²

Doutoranda em Letras pela Universidade de Santa Cruz do Sul (UNISC). Mestre em Letras pela Eniversidade Católica de Pelotas (UCPEL, 2014). Licenciatura em Letras Português/Espanhol pela Universidade Federal do Pampa (UNIPAMPA). Professora do Instituto Federal Sul-Rio-Grandense (IFSUL), campus Santana do Livramento. E-mail: faby_unipampa@h

Orientadora da dissertação de mestrado que resultou neste artigo. Doutora e mestre em Linguística Aplicada pelo Programa de PósGraduaçaao da Pontificia Universidade Católica do Rio Grande do Sul (PUCRS, 2014). Especialista Universidade Regional Integrad e das Missōes (2005). Professora adjunta da Universidade Tecnológica Federal do Paraná. Contato: susiele.machry@gmail.com
RESUMO: Este artigo apresenta os resultados obtidos em uma dissertação de Mestrado* (SILVA, 2014). Partindo do pressuposto de que falantes nativos do português, quando expostos ao ensino formal do espanhol, costumam encontrar dificuldade para reconhecer as diferenças entre as possibilidades fonológicas e alofônicas de ambas as línguas (COSTA, 2013; GOMES, 2013; MIRANDA, 2001; SILVEIRA e SOUZA, 2011), investigou-se se falantes brasileiros, aprendizes de espanhol como língua estrangeira, seriam capazes de reconhecer diferenças entre os sons /s/ - /z/; /l/ - /w/ e /R/ - /r/. Para tanto, foram aplicados dois testes de percepção. 0 primeiro teste abarcou o reconhecimento de frases (produzidas em uma única língua ou mescladas); já o segundo, consistiu na discriminação de sons em pares de palavras, seguido por uma tarefa de identificação do idioma (espanhol ou português). A seguir, realizou-se uma entrevista com cada informante, a fim de verificar se esse seria capaz de justificar suas respostas. Para a realização da análise estatística, utilizou-se o programa SPSS. Com relação à análise qualitativa, realizou-se uma adaptação dos níveis de Representação Mental propostos por Karmiloff-Smith (1992). A análise estatística evidenciou não haver diferença significativa no desempenho dos informantes no que tange às variáveis observadas.

Palavras-chave: Consciência Fonológica; Representação Mental; Percepção de sons em língua estrangeira; Ensino e aprendizagem de língua estrangeira.

ABSTRACT: This article presents results obtained in a Masters dissertation (SILVA, 2014). Assuming that Portuguese native speakers exposed to formal Spanish study commonly encounter difficulties in identifying the differences between phonological and allophone patterns in both languages (COSTA, 2003; GOMES, 2013; MIRANDA, 2001; SILVEIRA \& SOUZA, 2011), the study investigated if Brazilian speakers learners of Spanish as a foreign

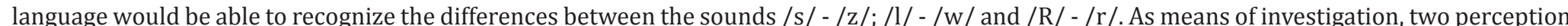
tests were administered. The first test encompassed the identification of sentences (produced in one language alone or mixed); the second, focused on the differentiation of sounds in pairs of words, followed by a language identification task (whether it was Spanish or Portuguese). Next, the subjects were each interviewed in order to verify if they were able to justify their answers. SPSS software was used to data analyses. As regards to the qualitative analysis, we adapted the Mental Representation levels proposed by Karmiloff-Smith (1992). The statistic analysis majorly revealed that there is no significant difference in performance in the observed variables.

Keywords: Phonological Consciousness; Mental Representation; Perception of sounds in foreign languages; Foreign languages' teaching and learning.

* A dissertação, na íntegra, pode ser encontrada no site <http://pos.ucpel.edu.br/dissertacoes-ppgl/?pasta=L01lc3RyYWRvLzIwMTQ=>. 


\section{Introdução}

E studos realizados acerca do ensino e da aprendizagem de línguas estrangeiras no Brasil têm aumentando significativamente a cada ano, bem como o interesse de pesquisadores por temas relacionados aos processos pelos quais passam os aprendizes dessas línguas. Contudo, ainda hoje, grande parte das pesquisas realizadas, particularmente sobre consciência fonológica e línguas estrangeiras, costuma ser dedicada quase que exclusivamente aos aprendizes de língua inglesa (CRISTÓFARO-SILVA, 2005; AQUINO e ZIMMER, 2005; ZIMMER, 2008; ALVES, 2004, 2009; BATTISTELLA, 2010). Assim sendo, de acordo com Roazzi e Dowker (1989), torna-se importante a realização de pesquisas com falantes de diferentes línguas, visto que os resultados podem variar devido aos fatores peculiares a cada língua, o que não permitiria a generalização dos resultados advindos de um único código linguístico.

No que tange ao ensino formal de espanhol como língua estrangeira, voltado a falantes nativos do português, ainda há poucos estudos sobre o desenvolvimento da consciência fonológica. Dentre as pesquisas realizadas acerca da consciência fonológica em português e em espanhol, destacase, como exemplo, o estudo de Silveira e Souza (2011) sobre a percepção e a produção das fricativas alveolares da língua portuguesa por falantes de espanhol. Já no que tange à aprendizagem de espanhol por falantes nativos do português, tem-se o trabalho desenvolvido por Miranda (2001) acerca da representação das consoantes róticas nos sistemas de crianças brasileiras e argentinas. Assim sendo, pode-se dizer que ainda há muito a se pesquisar nesse campo de conhecimento, especialmente, no que se refere à consciência fonológica e ao ensino e à aprendizagem de espanhol no caso dos falantes brasileiros.
A Consciência linguística, por sua vez, é considerada, neste estudo, como a capacidade que um sujeito tem de refletir sobre a língua e de manipular as diferentes unidades que a constituem. Nas palavras de Scliar-Cabral (1999), essa é uma habilidade metalinguística, na qual o ser humano tem de utilizar a linguagem para refletir sobre a própria linguagem de forma consciente. Seguindo nessa linha raciocínio, a consciência fonológica "pode ser caracterizada como a representação consciente das propriedades fonológicas e das unidades constituintes da fala" (FREITAS, 2003, p. 156). Segundo Freitas (ibid), essa habilidade permite ao falante reconhecer e manipular sons, como, por exemplo, identificar quais palavras rimam, terminam ou começam com o mesmo som dentro de um conjunto de palavras.

Embora essas habilidades tenham estreitas relações com o ensino e com a aprendizagem de línguas, muito raramente os professores atentam às pequenas partículas que compõem as palavras. Contudo, quando surgem situações nas quais os alunos precisam "realizar a correspondência entre os sons da fala e as letras, ou quando é necessário aprender a articular os sons de uma língua, é preciso pensar sobre a língua em detalhes, nos mínimos contrastes" (SCHERER, 2009, p. 25). Desse modo, este trabalho justifica-se mediante a necessidade de se desenvolverem estudos que abarquem os níveis de consciência fonológica, níveis de representação mental (KARMILOFFSMITH, 1986) e a sua relação com o processo de aprendizagem do espanhol como língua estrangeira $(\mathrm{LE} / \mathrm{L} 2)^{1}$ - área em que os estudos ainda são escassos. Entendendo-se, também, que, se o professor souber identificar os níveis de consciência fonológica que os aprendizes tendem a apresentar em qualquer que seja a língua estrangeira, em diferentes tarefas e contextos, terá possibilidade de adotar procedimentos adequados às necessidades desses sujeitos, podendo, assim, auxiliá-los em sua aprendizagem.

Este estudo não diferencia os termos segunda língua (L2) e língua estrangeira (LE). 
Tendo em vista as questões apresentadas, desenvolveu-se, em uma dissertação de Mestrado (SILVA, 2014), um trabalho de pesquisa cujo objetivo principal era investigar se falantes brasileiros, crianças e adultos, aprendizes de espanhol como língua estrangeira, seriam capazes de reconhecer diferenças entre os pares de sons /s/ - /z/; /l/ - /w/ e /R/ - /r/, quando apresentados em variados contextos (juntos e em separado). Em suma, a finalidade do referido estudo era investigar os níveis de consciência linguística e de representação mental dos aprendizes em LE, por meio de experimentos que envolvessem tanto o reconhecimento de sons, quanto a identificação do idioma.

Cabe destacar que essa pesquisa partiu da hipótese de que os adultos, por já terem as categorias linguísticas formadas, seriam capazes de reconhecer mais facilmente unidades menores, tais como fonemas e suas possibilidades alofônicas, devido à complexidade dessas e, também, devido ao tempo de estudo (contato formal) que esses sujeitos já possuíam com a língua materna e a habilidade escrita. Com base em diversos estudos que comprovam haver uma forte relação entre o nível de consciência fonológica e o desenvolvimento linguístico, de modo particular, em se considerando o processo de aquisição do código escrito (BLANCO-DUTRA, 2009; CARDOSO-MARTINS, 1995; FREITAS, 2004; LEMLE, 2003; MORAIS, 1996), acreditava-se que os sujeitos que estivessem em níveis de estudo mais avançados em língua espanhola e possuíssem mais tempo de contato com o idioma fora da sala de aula, tenderiam a apresentar maiores níveis consciência e de representação mental sobre os sons dessa língua e, por consequência, perceberiam mais facilmente as diferenças entre os pares de sons investigados, uma vez que esses sujeitos já teriam desenvolvido em sua língua materna a "capacidade de tomar a língua como objeto de estudo" (ALVES, 2009, p. 203) e, portanto, seriam mais sensíveis aos detalhes formais da língua-alvo.

\section{Aporte Teórico}

\subsection{Breves considerações sobre consciência linguística, consciência fonológica e consciência fonêmica}

Quando se está em um ambiente informal, como, por exemplo, conversando com um amigo ou colega de trabalho, muito raramente alguém se atém ao código linguístico utilizado, isto é, dá-se pouca importância à estrutura interna das palavras, ao modo como as mesmas são formadas, organizadas ou, ainda, manipuladas de acordo com as intenções dos falantes. Todavia, o ser humano é capaz de ir muito além, visto que é dotado da capacidade de refletir criticamente sobre um código linguístico, tomando-o, inclusive, como objeto de análise (ALVES, 2009). Assim sendo, de acordo com o referido autor, pode-se dizer que o falante é capaz de:

(...) refletir sobre e manipular, de forma controlada e deliberada, os aspectos do código linguístico, o que permite descobertas sobre a estrutura e suas relações com o funcionamento e o uso da língua. 0 indivíduo possui, portanto, habilidades de reflexão e manipulação do código em seus diferentes aspectos, o que caracteriza a consciência linguística (ibid, p. 32, grifo do autor).

A consciência linguística, portanto, consiste na capacidade de refletir sobre a língua e de manipular as diferentes unidades que a constituem. Por esse entendimento, pode-se dizer que as capacidades de produção, de pensamento e de manipulação de certa estrutura, são aspectos fundamentais para o campo da consciência linguística, aspectos esses que a diferem de outras áreas.

Com o passar do tempo, diversas designações surgiram em torno dessa área, destacando-se o conceito proposto por Tunmer e Herriman (1984, apud LORANDI, 2011) como um dos mais difundidos ainda nos dias atuais. Segundo esses pesquisadores, consciência linguística é a capacidade de pensar sobre e de manipular determinada estrutura. Ainda de acordo com os referidos autores, essa habilidade pode implicar diferentes níveis de 
consciência metalinguística, tais como consciência fonológica, morfológica, sintática, metatextual e pragmática.

No que se refere à consciência fonológica, por exemplo, essa pode ser classificada em três níveis, a saber: consciência da sílaba; consciência intrassilábica e consciência fonêmica. Conforme Supple (1986), esses graus de complexidade se desenvolvem gradualmente, isto é, aos poucos a criança vai se tornando consciente de frases, palavras, sílabas e fonemas, considerando-os como unidades identificáveis.

De modo geral, a consciência de sílaba diz respeito à capacidade que o falante tem de segmentar as palavras em sílabas, sendo essa uma das primeiras habilidades de consciência fonológica que as crianças desenvolvem precocemente. Quanto à consciência no nível intrassilábico, essa abrange constituintes silábicos, ou seja, unidades menores que a sílaba e maiores que um único segmento. Logo, o nível intrassilábico pode ser subdividido em consciência dos constituintes silábicos, como, por exemplo, a consciência da rima e a consciência das aliterações.

Para este estudo, importa somente a consciência fonêmica, a qual "corresponde à capacidade de reconhecer e manipular as menores unidades de som que possuem caráter distintivo na língua" (ALVES, 2009, p. 44). É importante salientar que, neste trabalho, os termos "consciência fonológica" serão frequentemente utilizados para representar "consciência fonêmica" em razão da pouca literatura encontrada sobre a última. Em outras palavras, a maior parte dos estudos encontrados envolve a consciência fonológica de um modo mais geral.

Seguindo a linha de raciocínio, Rueda (1995, p. 63) define consciência fonológica como sendo "a habilidade de manejar explicitamente as estruturas internas da palavra e, em consequência, não ter dificuldade de operar com ela”. Já na concepção de Scherer (2009), para falar em consciência fonológica é necessário que o falante ignore o significado de uma dada palavra e preste atenção à sua estrutura. De acordo com essa pesquisadora, o falante precisa estar consciente de que a palavra é constituída de elementos menores que podem ser segmentados e manipulados isoladamente.

Em resumo, enquanto habilidade cognitiva, a consciência fonológica permite a reflexão sobre os sons da fala, envolvendo diferentes habilidades que podem ser testadas por meio de diferentes tarefas de identificação e de produção de sons (FREITAS, 2003). Esse tipo de habilidade permite ao falante reconhecer e manipular sons, como, por exemplo, identificar que palavras rimam, terminam ou começam com o mesmo som dentro de um conjunto de palavras. Essas habilidades, quando desenvolvidas na língua materna, podem auxiliar na aprendizagem da L2. No entanto, isso não garante que se o aprendiz obtiver altos níveis de consciência fonológica em sua língua materna, terá o mesmo desempenho na língua estrangeira.

Antes de finalizar esta subseção, é importante destacar que, ao longo de suas pesquisas, Lorandi (2011) verificou que, embora haja um possível consenso na definição de "consciência linguística", o mesmo não ocorre quando o assunto envolve o modo e o momento em que essa emerge (NESDALE e TUNMER, 1984 apud LORANDI, 2011). Contudo, mesmo havendo três grandes perspectivas em torno do conceito de "consciência linguística", a autora percebeu que existe um ponto em comum entre elas: todas sustentam a existência de apenas dois níveis de consciência: o nível implícito e o nível explícito. Tal constatação motivou o surgimento de diversas pesquisas sobre o assunto. Dentre os recentes estudos realizados em torno dessa temática, destaca-se o modelo de Redescrição Representacional (RR) proposto pela pesquisadora Karmiloff-Smith $(1986,1992)$, conforme será abordado a seguir.

\subsection{Modelo de Redescrição Representacional (RR)}

O modelo de Redescrição Representacional (KARMILOFF-SMITH, 1986) consiste em um processo pelo qual uma dada informação, que está 
implícita na mente do sujeito, torna-se, subsequentemente, informação explícita, ou seja, aquele conhecimento sobre o qual não se tinha acesso passa a estar disponível para o acesso consciente. Assim sendo, "o modelo RR tenta descrever o modo pelo qual as representações das crianças tornamse mais manipuláveis e flexíveis para a emergência do acesso consciente do conhecimento" (LORANDI, 2011, p. 6). Em suma, o referido modelo tem como objetivo de entender como o desenvolvimento cognitivo ocorre.

De acordo com essa recente proposta, para analisar um determinado fenômeno, é preciso, antes de tudo, observá-lo a partir de um viés desenvolvimental, que possa fornecer um suporte aos aspectos inatos e construídos na explicação da cognição humana (LORANDI e KARMILOFFSMITH, 2012). Segundo essa teoria, existem certas pré-disposições cerebrais tanto de domínio específico, quanto de domínio geral.Com base na perspectiva da mente de uma criança, pode-se dizer que um domínio é um conjunto de representações que sustentam uma determinada área do conhecimento, tais como a linguagem, a matemática, a física, etc. Isto significa dizer que o cérebro passa por um processo de modularização gradual, processo pelo qual as estruturas cerebrais vão se especializando em determinadas funções.

Conforme esse modelo, existem quatro níveis em que o conhecimento é (re)representado. O primeiro nível (Implícito I) abrange o conhecimento enquanto forma procedimental, em que só é possível analisá-lo como um todo. No segundo nível, (Explícito 1) já se tem representações explícitas, porém, essas ainda não se encontram acessíveis para uso consciente, tampouco para exposição verbal. No nível Explícito 2, as representações explícitas já estão acessíveis de forma consciente, todavia, ainda não estão disponíveis para relato verbal. Já no último nível, (Explícito 3), tem-se acesso consciente ao conhecimento e o sujeito já é capaz de relatá-lo verbalmente.

É importante salientar que essas formas de representação não constituem estágios relacionados com a idade do sujeito, uma vez que essas fazem parte de um processo cíclico e contínuo. Por conseguinte, "no momento em que, um certo nível, em termos de comportamento dentro daquele domínio, é atingido, o conhecimento é, então, redescrito de uma forma que se torna acessível para o próximo nível" (LORANDI, 2011, p. 6). Com base nesse conceito, acredita-se que a consciência linguística emerja desde cedo na criança, concomitante ao processo de aquisição da linguagem.

\subsection{Sistemas consonantais do português e do espanhol}

O sistema fonológico do português é composto por 19 fonemas consonantais e por 7 fonemas vocálicos (MATTOSO CÂMARA JR, 1984). Alguns desses fonemas, por sua vez, podem apresentar mais de uma forma e são denominadas alofones. O português brasileiro (PB) possui muitos alofones e isso pode dificultar a aprendizagem dessa língua como LE. Essa complexidade é explicada pelo fato de que os mesmos sons considerados fonemas em uma língua podem apresentar diferentes realizações alofônicas em outra (FERNÁNDEZ, 2001, p. 83). Nesse caso, o aprendiz precisa não só adquirir os fonemas da língua, mas também reconhecer suas diferentes possibilidades.

O sistema fonológico do espanhol, por sua vez, apresenta-se em menor número, sendo composto por 17 consoantes e por 5 vogais. Quanto aos alofones, dentre as consoantes/s/, /l/, / / / e /R/ , destacam-se apenas três possibilidades de variação para /l/, tais como [1], [ł] e [1]; ; enquanto que para /r/ não é registrado nenhuma variação.l

\subsection{Pares consonantais: contraste /s/ e /z/, /l/ e /w/ e /r/ e /R/}

A dificuldade entre os sons /s/ e /z/ acontece em duas direções, a saber, (i) o aprendiz brasileiro, por partir de um sistema fonológico maior, pode transferir a produção desses sons para o espanhol; (ii) já o aprendiz hispanofalante, esse precisa adquirir o fonema /z/não existente em sua língua. Logo, 
esses aprendizes terão de criar novas categorias fonético-fonológicas e isso pode dificultar a aprendizagem da L2.

As consoantes líquidas, por sua vez, formam uma classe especial em diversas línguas devido à sua facilidade para combinar-se com outras consoantes e formar os chamados encontros consonantais (GOMES, 2013). As líquidas abarcam as laterais /1,'/, os glides /j, w/ e os vários tipos de /r/. Essas consoantes compartilham entre si o traço aproximante (LADEFOGED, 1975 apud BISOL, 2010), aspecto esse que pode motivar o aparecimento de alofones, como é o caso da troca da líquida /1/ pelo glide /w/ no PB, quando essas se encontram em posição final de sílaba (salto/sal). Consequentemente, falantes brasileiros, aprendizes de espanhol como LE, acabam realizando /w/ no lugar /1/ também na língua-alvo.

No que tange às consoantes róticas, essas apresentam similaridades acústicas e padrão fonológico muito parecidos com as consoantes laterais, constituindo também a classe das líquidas. A consoante vibrante é um fonema com número relativamente grande de realizações fonéticas, tendo ocorrência e frequência diferenciada por dialetos (BISOL, 2010). Mattoso Câmara Jr. (1984), após muitos anos de estudo, constatou a existência de duas vibrantes no PB que se opõem entre vogais e se neutralizam nas demais posições de sílaba. Essas vibrantes são posteriormente denominadas como ' $r$ ' fraco e ' $r$ ' forte (MIRANDA, 2001). Segundo a autora, "os, r"s forte e fraco contrastam unicamente em ambiente intervocálico".

Em contrapartida, em espanhol, "estes dois fonemas têm sua importância própria e a troca de um pelo outro, em determinados contextos, pode produzir uma compreensão incorreta por parte do ouvinte" (GOMES, 2013, p. 13). Isto significa dizer que, enquanto os fonemas / $\mathrm{r} / \mathrm{e} / \mathrm{R} /$ podem ser encontrados como variáveis fonéticas em determinadas posições silábicas do português, em espanhol essa troca não é permitida, visto que ambos os sons são fonemas diferentes nessa língua, independentemente de sua posição.
Tendo em vista essa diferença entre as línguas, esse estudo partiu do pressuposto de que o contraste /R/ e / $\mathrm{r}$ / seria o par que envolveria maior dificuldade no que diz respeito ao reconhecimento de suas diferenças por falantes brasileiros. Essa complexidade se daria em virtude de esses dois sons existirem em ambas as línguas e de, no português, apresentarem diferentes possibilidades alofônicas (variações que ocorrem para o mesmo fonema, sem alteração do sentido). De acordo com Harris (1983), os pares mínimos, em espanhol, são abundantes, como pode ser observado a seguir:

Tabela 1 - Diferentes realizações e significados a partir dos sons /R/ e /r/

Palavras realizadas com o som [R] e seus $\quad$ Palavras realizadas com o som $[\mathrm{r}]$ e seus
respectivos significados*

[R]aro**

Vasilha semelhante a uma jarra.

[r]aro

Extraordinário, singular, pouco comum ou

Co[R]er

Segurar algo (pessoa ou objeto); pegar um

ônibus ou táxi; Contrair uma enfermidade, etc.

[R]ota

0 nome da letra jota (J) em espanhol. frequente.

Co[r]er

Andar rapidamente, com pressa, realizar uma corrida.

[r]ota

Que está quebrada ou partida em duas ou mais partes (substantivo Feminino). Deixou de funcionar. Está muito cansada.

\section{Pe[R]o}

Significa cão ou cachorro. Também pode ser atribuída a uma pessoa indigna, depreciável.

\section{A[R]o}

Bulbo de alho cultivado, de cheiro e gosto forte e Peça de ferro ou de outra matéria rígida, em persistente, composto de um número de bulbos

\section{Pe[r]o}

Elemento (Mas) que une duas orações ou sintagmas cujos significados se contrapõem, se restringem ou se limitam.

\section{$\mathrm{A}[\mathrm{r}] \mathbf{0}$}

menores (dentes)

* Essas palavras podem receber outros significados além dos aqui apresentados, conforme pode ser visualizado em vários dicionários online, tais como <http://michaelis.uol.com.br/moderno/portugues/> e <http://www.

wordreference.com/ptes/>.
**É importante destacar que, embora o primeiro som da palavra [R]aro seja uma consoante fricativa, optou-se por representá-lo como consoante líquida para facilitar o entendimento desse trabalho e a análise dos dados. Fonte: Silva (2014). 
Em resumo, pode-se dizer que, diferentemente do espanhol, o sistema consonantal do português brasileiro apresenta variantes para /R/ e /r/ condicionadas por fatores linguísticos ou não linguísticos com distribuição variável de acordo com o dialeto e também de acordo com o ambiente linguístico. Isto significa dizer que, enquanto os fonemas $/ \mathrm{r} / \mathrm{e} / \mathrm{R} /$ podem ser alofones no PB (ga[r]afa / ga[R]afa), em espanhol essa troca não é permitida, visto que esses sons são fonemas diferentes nessa língua (co[r]er / co[R]er), independentemente de sua posição silábica.

\section{Metodologia}

Nesta seção, serão delimitados os sujeitos observados, os procedimentos de pesquisa, os instrumentos aplicados, e, por fim, apresentados os resultados obtidos ao longo da pesquisa em questão.

\subsection{Sujeitos do estudo}

A pesquisa contou com a participação de seis crianças e seis adultos, todos tinham nacionalidade brasileira e estudavam em uma escola de idiomas localizada no município de Bagé/RS, cidade geograficamente próxima da fronteira Brasil/Uruguai, mas de pouco contato com a língua espanhola. Salienta-se que esses informantes não eram falantes nativos de espanhol e tampouco possuíam fluência oral e/ou escrita no idioma. As crianças possuíam idade entre 10 e 13 anos e estavam cursando entre o 5ํ e o 8o ano do Ensino Fundamental. Já no grupo de adultos, devido ao programa seguido pela escola, as idades eram bastante diferentes, uma vez que as turmas eram compostas por sujeitos acima de 14 anos. Em resumo, o grupo de crianças tinha uma idade média de 11,5 anos e desvio padrão de 1,04 , enquanto que a idade média dos adultos era de 25,3 anos, com desvio padrão de 8,64. Tendo em vista tal disparidade, optou-se pela separação dos informantes em grupos (adultos e crianças) e em níveis de estudo da LE (básico e pré-intermediário).

\subsection{Procedimentos de pesquisa}

Primeiramente, realizou-se a revisão bibliográfica que embasaria o estudo, tendo em vista os objetivos delineados, bem como o corpus em questão. A seguir, a pesquisa passou pela avaliação e aprovação do CEP (Comitê de Ética). No caso do grupo de crianças, por tratar-se de um grupo de sujeitos menores de 18 anos, foi necessário que os pais e/ou responsáveis por esses alunos assinassem um Termo de Consentimento Informado. No que tange aos informantes com idade acima de 18 anos, esses tiveram de assinar um Termo de Consentimento Livre e Esclarecido, no qual autorizavam a utilização de seus dados em proveito dessa pesquisa.

Posteriormente, foram desenvolvidos e aplicados dois questionários, um voltado às crianças e outro aos adultos. Esses, por sua vez, abrangiam tanto os dados pessoais de cada sujeito (tais como idade, escolaridade, etc.), como também o contato que esse com a língua espanhola fora da sala de aula. A seguir, foram aplicados dois testes de percepção fonético-fonológica, conforme será detalhado na próxima subseção.

Por último, realizaram-se entrevistas individuais com os sujeitos pesquisados. Essa tarefa permitiu outro tipo de análise resultante do cruzamento de dados, esses que, por sua vez, haviam sido coletados a partir do desempenho que os referidos sujeitos haviam apresentado nos testes anteriores. Mais detalhes sobre os experimentos aplicados serão fornecidos nas próximas seções.

\subsubsection{Definição do primeiro teste}

O primeiro teste foi composto por 24 frases que foram gravadas em um CD e, posteriormente, apresentadas aos alunos. Desse total de frases, 
quatro foram pronunciadas totalmente em português; quatro inteiramente em espanhol; quatro estavam mescladas (frase em espanhol e palavra em português); E, quatro mescladas (frase em português e palavra em espanhol). Se a resposta fosse, por exemplo, "frase mesclada", eles deveriam marcar essa opção na ficha que lhes havia sido entregue e identificar qual palavra havia sido pronunciada na outra língua, conforme pode ser visualizado na Figura 1.

Figura 1 - Exemplo de questão proposta no primeiro teste

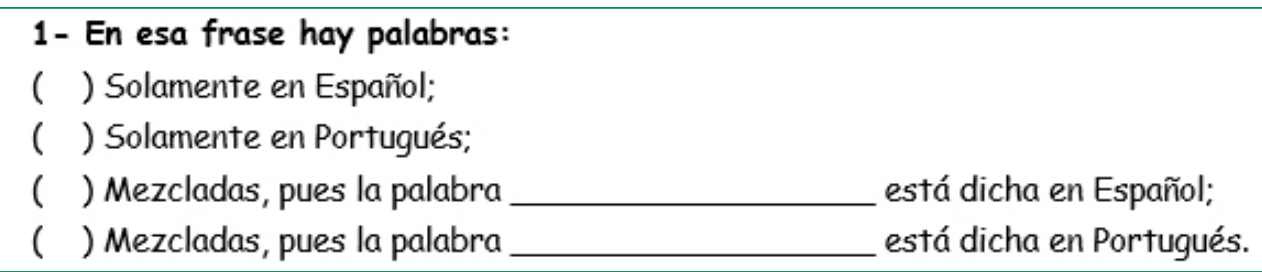

Fonte: Silva (2014).

Desenvolveu-se esse teste com o intuito de observar se os sujeitos informantes seriam capazes de perceber e de reconhecer as diferenças, em nível fonético-fonológico, entre a língua portuguesa e a língua espanhola, quando fossem mescladas palavras dessas línguas em uma mesma frase, ou seja, quando fossem apresentados os sons de uma língua, porém, no contexto frasal de outra.

As tarefas foram realizadas individualmente, durante o período de aula. Antes de ir para sala de informática, foi realizado um treinamento com os alunos. Nesse caso, a pesquisadora escrevia no quadro-branco as opções citadas acima e, a seguir, entregava aos informantes quatro placas, contendo as letras A, B, C e D.

Após a realização dessa atividade de pré-aquecimento, as turmas eram conduzidas ao laboratório de informática. Nesse ambiente, cada participante dispunha de um computador e de um fone de ouvido e, podia escutar até três vezes cada gravação. Procedeu-se dessa maneira a fim de evitar que situações adversas (ruídos, comentários dos outros colegas, etc.) pudessem interferir no desempenho dos informantes. É importante destacar que todas as frases foram cuidadosamente gravadas e editadas, por meio do software Audacity, antes de serem apresentadas aos sujeitos investigados.

Assim que os informantes terminavam de ouvir todas as gravações e de preencher toda a ficha que lhes havia sido entregue para a realização da atividade proposta, esses eram liberados da sala. Quando possível, a investigadora realizava perguntas sobre possíveis dificuldades que os informantes pudessem ter encontrado para realizar as atividades propostas, bem como sobre a qualidade das gravações que lhes haviam sido apresentadas.

\subsubsection{Definição do segundo teste}

Primeiramente, os informantes escutavam um par de palavras que contivesse os segmentos-alvo (em português, em espanhol, ou mesclados). Logo após, indicavam se esses segmentos eram iguais ou diferentes (FLEGE, 1995). Foram propostas, no total, 32 atividades. Dentre essas, 16 envolviam pares de palavras nas quais os informantes deveriam observar se os sons dessas eram iguais ou diferentes (ex. mal/sal; guerra/garra/; casa/casamento); As outras 16 abarcavam somente uma palavra que deveria ser identificada como pertencente a uma das línguas. Para desviar a atenção do informante com relação ao foco analisado, foram inclusos oito estímulos distratores.

Cabe destacar que tanto o software PRAAT2 quanto o $T P^{3}$, (Teste/Treinamento de Percepção), embora sejam ferramentas desenvolvidas para a

${ }^{2}$ Ferramenta desenvolvida pelos linguistas Paul Boersma e David Weenink, do Institute of Phonetic Sciences, da Universidade de Amsterdam. Esse software está especialmente voltado à análise de som como ondas focando em parâmetros como frequência, comprimento, intensidade, etc. Mais informaç̃̃ podem ser obtidas nos seguintes sites: < http://www fon hum. gmhp/soft/praat.pdf $>$. gmhp/soft/praat.pdrs.

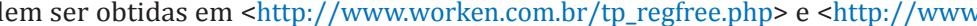
worken.com.br/tp/Tutorial_TP_VS31BR.pdf>. 
elaboração de instrumentos de percepção, essas não possibilitavam realizar os testes pretendidos nessa pesquisa. Levando em conta todos esses aspectos, decidiu-se utilizar o programa ELO (Ensino de Línguas Online) como suporte para a realização do segundo teste. Ainda que o referido software não tenha sido desenvolvido para esse fim, uma vez adaptado, o mesmo conseguiu dar conta dos objetivos do estudo e do teste proposto.

O ELO (Ensino de Línguas Online) é um sistema de autoria que permite ao professor elaborar atividades pedagógicas e interativas para os seus alunos. Esse programa de computador foi criado e batizado pelo pesquisador Leffa (2006) como uma Ferramenta de Autoria, devido ao fato de possibilitar a produção de arquivos digitais e multimidiáticos, podendo conter texto escrito, imagem, som e vídeo simultaneamente. 0 mesmo foi elaborado com o intuito de instrumentalizar o docente para ensinar línguas por meio da rede nacional de computadores e, também, de ampliar a sua ação para além da sala de aula, de modo a torná-lo presente até mesmo na Educação a Distância (EAD).

Em resumo, o segundo teste foi realizado por meio do sistema ELO e as atividades desenvolvidas foram de múltipla escolha. Nessas atividades, apresentava-se um par de palavras (explicitadas no enunciado da tarefa) com somente uma "letra" faltando. A proposta era que os informantes escutassem os dois estímulos e analisassem se os sons que estavam faltando nas duas palavras eram "diferentes" ou "semelhantes". A configuração do teste elaborado é representada na Figura 2.

Durante a execução das atividades, cada informante deveria clicar nas imagens (à direita) para escutar os estímulos e, a seguir, fazer um clique na opção ("iguales" ou "diferentes) com base na sua percepção de oitiva para os sons que faltavam em cada palavra apresentada. Independentemente de seu desempenho, o único feedback que o aluno recebia era iAdelante!, já que ele poderia ser influenciado por um feedback negativo, caso se equivocasse, por exemplo. Após haver concluído essa atividade, o sujeito deveria clicar em ">" para prosseguir.

Figura 2 - Exemplo de atividade proposta no segundo teste (identificação de sons)

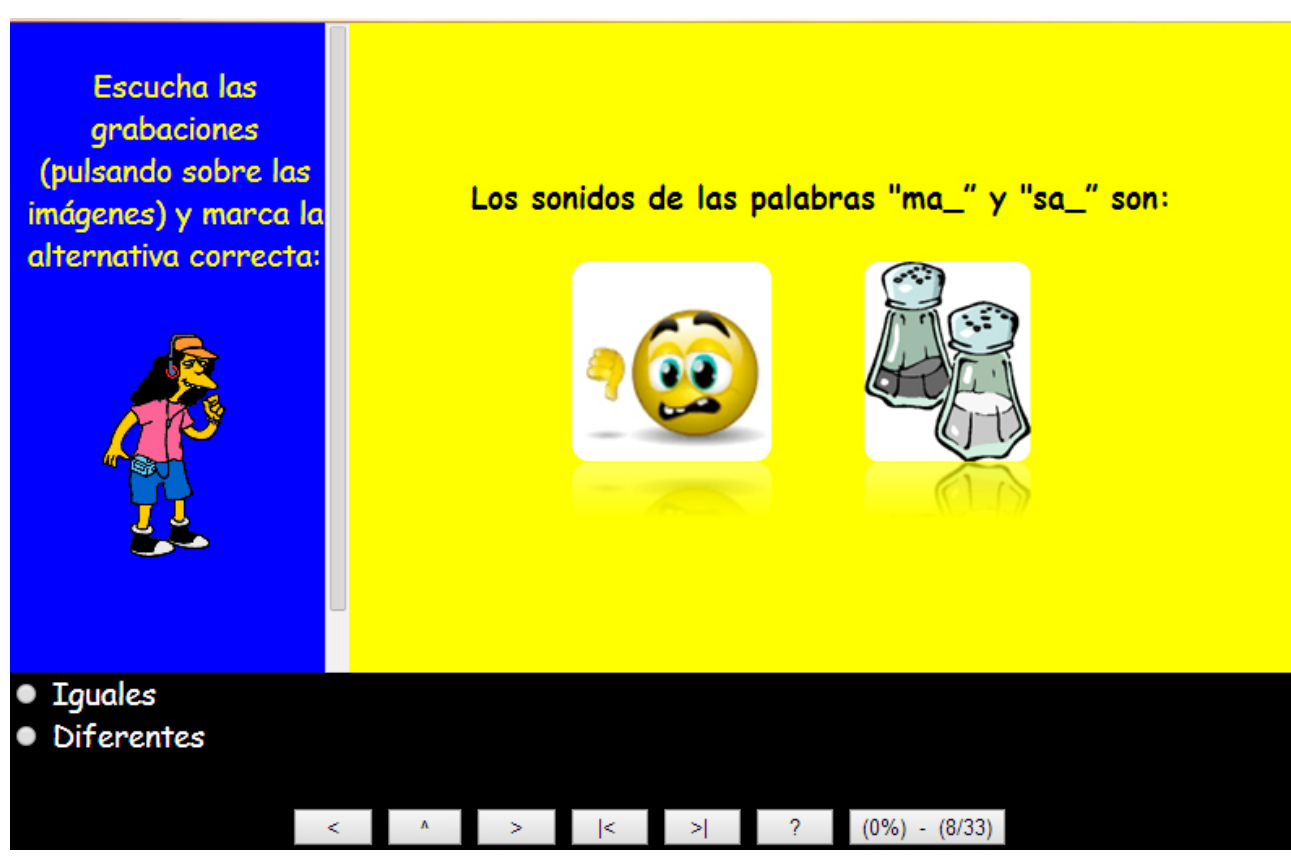

Fonte: Silva (2014).

Na continuidade do mesmo teste, após julgar se os estímulos eram "iguais" ou "diferentes", o informante deveria identificar a que língua (português ou espanhol) pertencia a palavra que ele tinha acabado de escutar, como pode ser visualizado no exemplo disposto na Figura 3, que representa a tela subsequente do experimento. 
Figura 3 - Exemplo de atividade de identificação de idioma

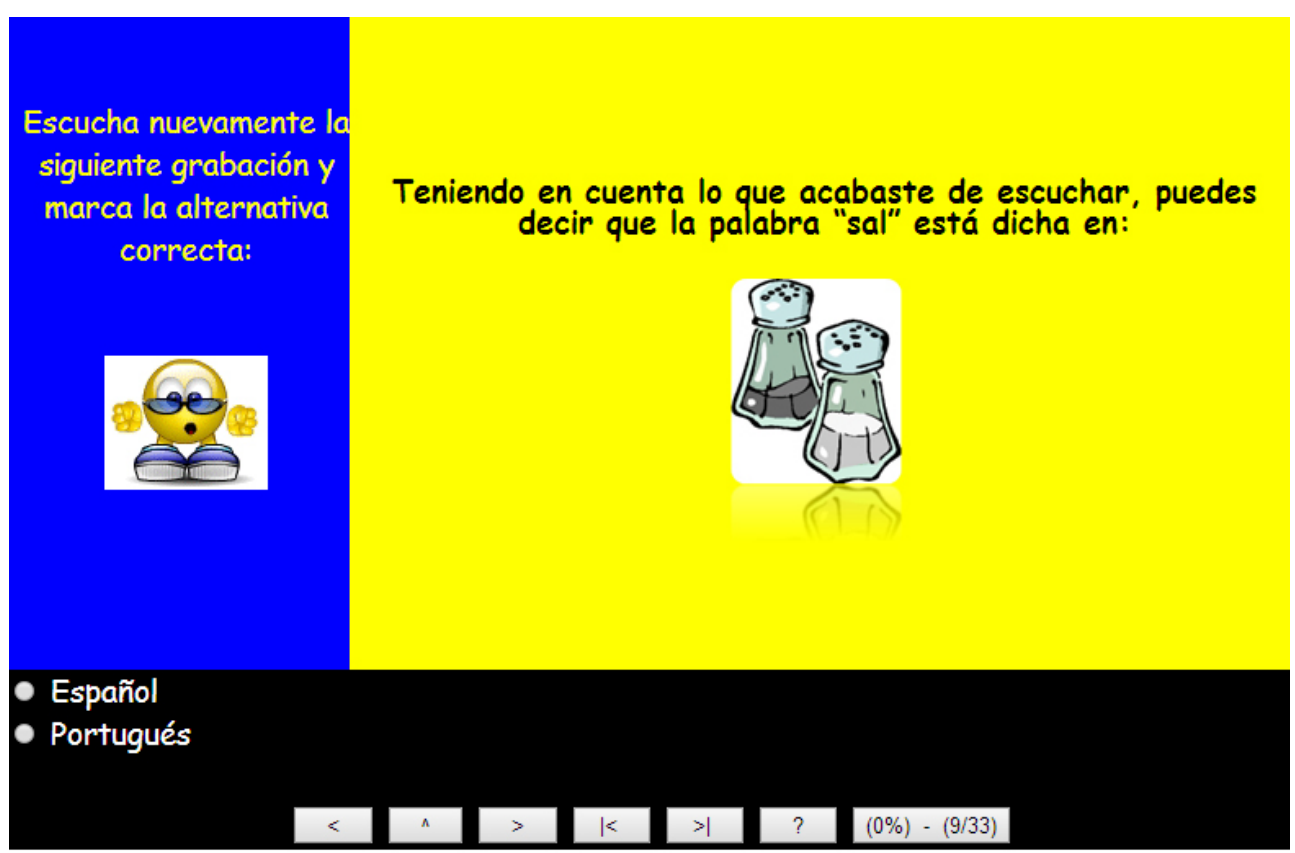

Fonte: Silva (2014)

Nessa segunda tarefa, era proposto que os informantes escutassem, novamente, uma das palavras exibidas na tela anterior do mesmo experimento. Nesse momento, além de ser apresentada apenas uma das palavras do par, o sujeito também teria contato com a palavra escrita. Dessa forma, no caso do exemplo /mal/ e /sal/, apresentou-se novamente a palavra "sal", solicitando ao informante a identificação do idioma. No caso, dada a variação alofônica apresentada na pronúncia do /l/, que ocorre no Português Brasileiro e não no espanhol, a resposta esperada seria "português".

É importante salientar que todas as palavras-alvo faziam parte do inventário linguístico de ambos os idiomas Além disso, essas palavras foram recortadas das frases apresentadas no primeiro teste com intuito de que as mesmas possuíssem entonações diferentes devido ao fato de terem sido produzidas em contextos distintos. Realizou-se esse procedimento a fim de diminuir a possibilidade de interferência no momento em que os informantes tivessem de identificar a que língua essas palavras pertenciam.

\subsubsection{Entrevista}

Após o término do teste anterior, realizou-se uma entrevista com cada sujeito informante, a fim de verificar se o mesmo seria capaz de explicar porque uma determinada palavra, segundo o que ele havia respondido, pertencia a uma língua e não a outra. Essas entrevistas foram realizadas individualmente, logo após a aplicação do segundo teste, com uma duração máxima de 5 minutos, tendo como norte seis questões que versavam sobre as respostas apresentadas pelos informantes no teste anterior. Em outras palavras, os mesmos deveriam responder se nas frases ouvidas (as mesmas apresentadas no primeiro teste) existiam palavras pertencentes ao português e/ou ao espanhol e, a seguir, justificar a sua resposta. Todas as entrevistas foram gravadas e, posteriormente, transcritas. Como se trata de uma estratégia de análise qualitativa e complementar aos testes realizados, somente os dados importantes para este estudo foram levados em conta no momento de esquematizar os resultados obtidos.

Esse tipo de atividade (entrevista) mostrou-se de suma relevância, uma vez que permitiu ao investigador averiguar se os sujeitos haviam realizado as tarefas com base no que realmente tinham aprendido e conheciam sobre a língua, ou se eles simplesmente acertaram a questão por intuição ou por sorte. Além disso, a referida atividade permitiu analisar os níveis de consciência linguística que os aprendizes apresentavam em diferentes situações, bem como comparar esses dados com o desempenho apresentado nos testes anteriores. 
Em suma, a entrevista possibilita ao informante explicar suas respostas, isto é, apresentar uma justificativa oral para o fato de, por sua avaliação, acreditar que uma dada palavra pertence a um ou ao outro idioma. Para tanto, o informante foi orientado a apresentar argumentos para sustentar a sua "tese", com base em conhecimentos diversos, especialmente, advindos do contato formal que possui com ambas as línguas.

Como é possível perceber, esse tipo de tarefa exige um grau maior de complexidade e, portanto, pode revelar se o sujeito avaliado é capaz de chegar ao nível explícito 3 de representação mental, nível máximo segundo Karmiloff-Smith K (1986), o que não seria possível averiguar por meio dos outros instrumentos, visto que a verbalização desse conhecimento torna-se necessária nesse nível de consciência.

\section{Descrição e análise dos resultados}

\subsection{Resultados obtidos no primeiro teste}

De modo geral, de um total de 288 questões propostas, os informantes acertaram 230 e se equivocaram em 58. Dessas 230 questões corretas, 63 envolviam o reconhecimento de frases somente em espanhol e 64 somente em português, o que totaliza 127 questões identificadas corretamente (55\%) como pertencentes a uma única língua.

Para efeito de análise, atribui-se, em percentual, uma nota máxima de $100 \%$ para o desempenho dos informantes em cada um dos pares de contraste analisados (/s/ - /z/; /l/ - /w/ e /R/ - /r/), de acordo com os contextos nos quais esses pares encontravam-se inseridos. A partir dessa análise, em termos percentuais, chegou-se aos resultados expostos na representação gráfica da Tabela 2 , apresentada adiante.

No referido gráfico, é possível visualizar que a maior média de acertos ocorreu em frases realizadas somente em uma língua, nesse caso, em espanhol e/ou em português. Quando a frase foi apresentada inteiramente em português, obteve-se média de $75 \%$ para o contraste /s/ e /z/ e de $96 \%$ para os contrastes /l/ e /w/ e /R/ e /r/. Para as frases apresentadas somente em espanhol, a média foi de $79 \%$ para o contraste /s/ e /z/; 87\% para o par /l/ e /w/ e $96 \%$ para o par /R/ e /r/.

Tabela 2 - Acertos obtidos no primeiro teste e o tipo de tarefa

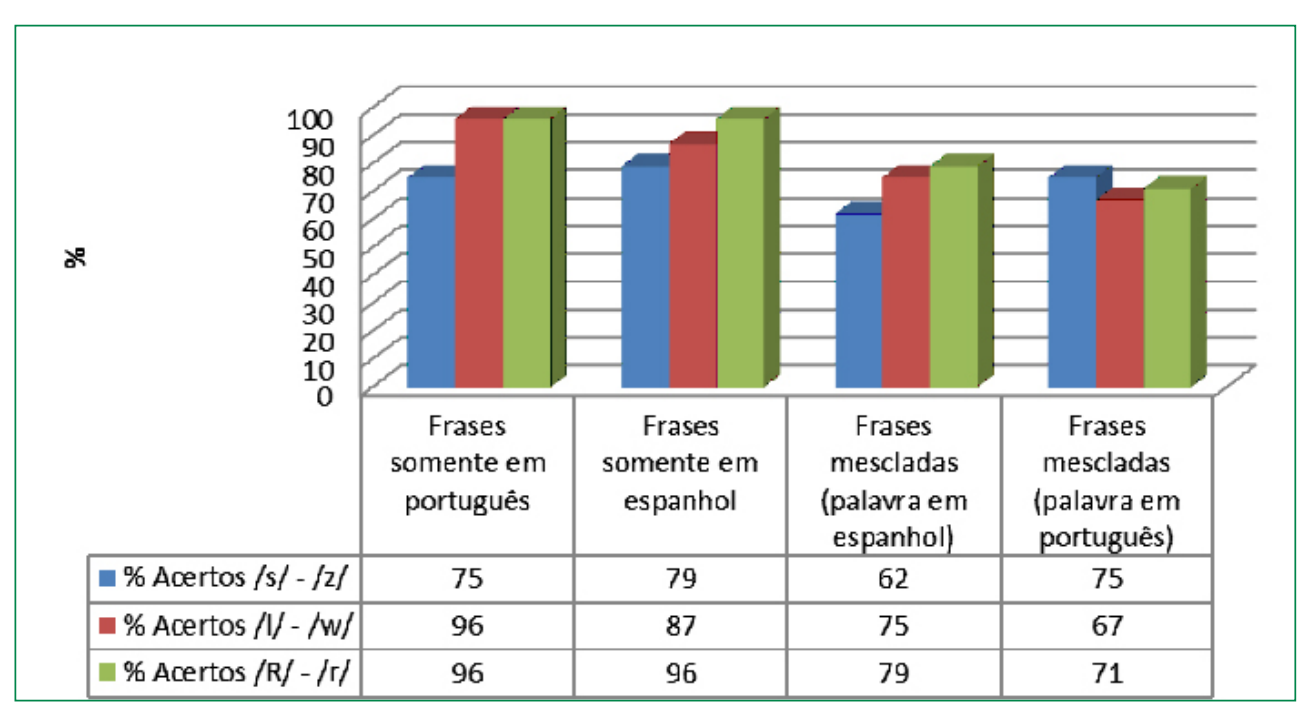

Fonte: Silva (2014).

As menores médias foram obtidas em tarefas que exigiam o reconhecimento de palavras apresentadas em frases mescladas. Nesse caso, para as frases em português, mescladas com palavra em espanhol, a média foi de $62 \%$ para /s/ e /z/; 75\% para /l/ e /w/ e de 79\% para /R/ e /r/. No que tange às frases em espanhol, mescladas com palavra em português, alcançou-se média de $75 \%$ para /s/ e /z/; de 67\% para /l/ e /w/ e de $71 \%$ para /R/e /r/. Frente a esses resultados, pode-se dizer que, de modo geral, os 
sujeitos investigados alcançaram melhores médias em tarefas que envolviam o reconhecimento de palavras contendo o contraste /R/ e /r/. Em resumo, os maiores índices de equívocos foram registrados no reconhecimento de frases mescladas e o par /R/ e / $\mathrm{r}$ / foi o que menos registrou erros em quase todos os tipos de tarefas propostas.

Com o objetivo de verificar se essa diferença era estaticamente significativa, desenvolveu-se, com o auxílio do software SPSS (Startical Product and Service Solutions) versão 17.0, o teste paramétrico T para amostras emparelhadas. Os resultados não demonstraram uma diferença estatisticamente significativa ( $p>0,05)$ entre o reconhecimento dos pares envolvidos, quando comparados entre si. Não se confirma, portanto, diferença no desempenho dos aprendizes quanto ao tipo de contraste.

\subsection{Resultados obtidos no segundo teste}

Nesse teste, observou-se que, das 250 questões respondidas corretamente, 76 ocorreram com o par /s/ e /z/; $85 \mathrm{com}$ o par /l/ e /w/ e 89 com o par /R/ e /r/. Quanto ao tipo de tarefa, percebeu-se uma grande diferença entre as atividades propostas. Em outras palavras, obteve-se 84 acertos para / $\mathrm{R} / \mathrm{e} / \mathrm{r}$ / na tarefa de reconhecimento de idioma, enquanto que para as tarefas de reconhecimento de sons o mesmo par alcançou apenas 5 acertos.

O número total de acertos evidencia ainda mais essa diferença, isto é, das 250 questões respondidas corretamente, 220 ocorreram em tarefas de reconhecimento de idioma e, apenas $30 \mathrm{em}$ tarefas de reconhecimento de sons. No que tange aos equívocos, dos 24 erros cometidos em tarefas de reconhecimento de sons, 14 abarcavam o contraste /s/ e /z/; 7 envolviam o par /l/ e /w/ e, apenas 3 continham /R/ e /r/.

A representação gráfica disposta na Tabela 3 possibilita a visualização do percentual de acertos obtidos no segundo teste, de acordo com o tipo de tarefa e com os pares de sons investigados.
Tabela 3 - Acertos obtidos no segundo teste, de acordo com o tipo de tarefa

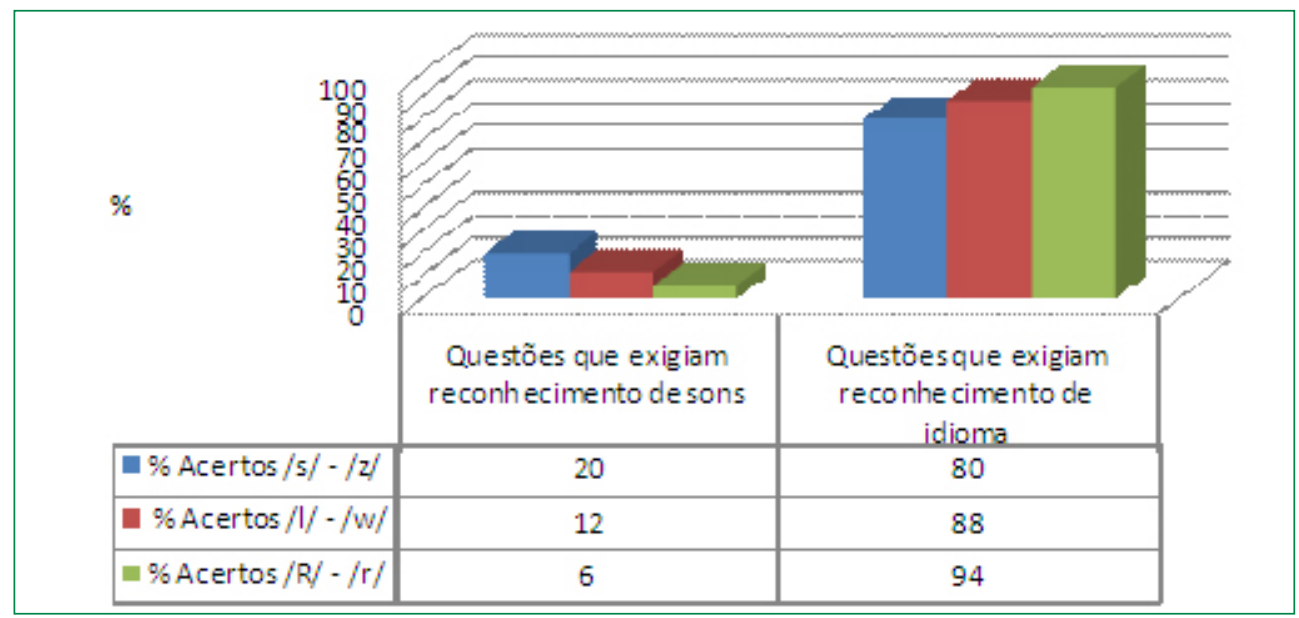

Fonte: Silva (2014)

Por meio do referido gráfico, é possível constatar que a maior média de acertos ocorreu em questões que exigiam o reconhecimento de idioma. Nesse caso, obteve-se média de $80 \%$ para o par de sons /s/ e /z/; $88 \%$ para o par /l/ e /w/ e 94\% para o par /R/ e /r/. Quanto às tarefas que exigiam o reconhecimento dos sons em palavras, obteve-se um desempenho inferior ao apresentado na tarefa de reconhecimento de idioma, com média de $20 \%$ para /s/ e /z/; 12\% para /l/ e /w/ e 6\% para /R/ e /r/.

No que tange aos contrastes em análise, para o segundo tipo de tarefa, o par mais facilmente reconhecido foi /R/ e /r/ e, em contrapartida, o par menos facilmente reconhecido foi /s/ e /z/. No entanto, vale salientar que se obteve um resultado distinto em se tratando de questões que envolviam o reconhecimento de sons. Diferentemente do outro tipo de tarefa (reconhecimento de idioma), nessa segunda proposta de tarefa, obteve-se a maior média para /s/ e /z/ (20\%); na sequência, a segunda maior média foi 
para /l/ e /w/ (12\%), enquanto que a menor média foi obtida para o par /R/ e $/ r /(6 \%)$. Isto significa dizer que o tipo de tarefa pode ter influenciado no desempenho dos informantes, de forma que um determinado par de sons, a exemplo de /R/ e / $\mathrm{r} /$, pode ser mais facilmente reconhecido em uma tarefa e menos reconhecido em outra.

Para verificar se essa diferença era estaticamente significativa, foram desenvolvidos, novamente, testes de diferença. Dessa vez os resultados comprovaram uma diferença significativa entre o reconhecimento do par de sons /l/ e /w/ (média 88,54) e o reconhecimento do par de sons /s/ e /z/ (média 79,16), o que indica que o primeiro par foi identificado mais facilmente. Quando comparados os pares /s/ e /z/ e /R/ e /r/, a diferença mostra-se novamente significativa. Nesse caso, entretanto, comprova-se que o contraste /R/ e /r/ (média 92,70) é mais facilmente reconhecido em relação ao contraste /s/ e /z/ (média 79,16). No que se refere à comparação dos pares /l/ e /w/ e /R/ e /r/, a diferença entre os dois contrastes mostrouse não significativa.

Quanto aos resultados observados por meio dos erros cometidos pelos participantes, pode-se dizer que esses corroboram a análise realizada anteriormente em relação aos acertos obtidos nesse segundo teste, isto é, os informantes podem apresentar capacidades de percepção diferentes não somente em relação a determinados pares de sons, mas também de acordo com o tipo de tarefa proposto.

\subsection{Análise das entrevistas}

De modo geral, as entrevistas foram realizadas individualmente e duraram aproximadamente 5 minutos. Essas, por sua vez, tiveram como norte seis questões que versavam sobre o que os informantes haviam respondido no teste anterior. Logo, as entrevistas foram compostas por duas tarefas; a primeira visava à identificação do idioma no qual as frases estavam sendo proferidas e, a segunda, foi desenvolvida com o intuito de possibilitar aos informantes justificar as suas respostas. Todas as entrevistas foram gravadas e, posteriormente, transcritas.

\subsubsection{Primeira tarefa}

Nessa tarefa, os informantes deveriam apenas identificar se as frases que eles estavam escutando haviam sido pronunciadas num único idioma, ou se continham palavras mescladas. Os resultados demonstram que, de 36 frases apresentadas, as crianças foram capazes de explicar corretamente 27. Dentre as seis frases apresentadas, em três delas o grupo obteve $100 \%$ de aproveitamento quando a tarefa envolvia a identificação do idioma ao qual as mesmas pertenciam. Se comparados os grupos, observa-se que o desempenho dos adultos foi relativamente superior ao apresentado pelas crianças (32). No que tange aos equívocos, enquanto os adultos cometeram somente quatro erros, as crianças cometeram nove.

\subsubsection{Segunda tarefa}

Nessa tarefa, pretendia-se averiguar se os sujeitos haviam acertado as atividades anteriores com base em conhecimentos sobre a língua ou por intuição/sorte. Assim sendo, os informantes deveriam justificar a resposta dada na tarefa anterior. Cabe ressaltar que, em razão dessa pesquisa ter como foco frases e sons e, não apenas palavras isoladas, os níveis de representação mental propostos pelo modelo de RR (KARMILOFF-SMITH, 1986; 1992) tiveram de ser adaptados.

Os resultados evidenciaram que o grupo de crianças foi capaz de explicar corretamente 24 frases de um total de 36. Dessas 24 frases explicadas corretamente, dezesseis puderam ser classificadas em nível explícito 3; cinco condisseram ao explícito 2; uma se enquadrou como explícito 1 e, seis corresponderam ao nível implícito, conforme pode ser visualizado na Tabela 4: 
Tabela 4 - Nível de consciência de sons (explicação) - Grupo crianças

\begin{tabular}{|c|c|c|c|c|c|c|c|c|}
\hline Sujeitos & Frases & $\begin{array}{l}\text { 1. Pessoas dignas estão } \\
\text { cada vez mais [r]aras. }\end{array}$ & $\begin{array}{l}\text { 2. Mi ca[z]a es verde y } \\
\text { blanca. }\end{array}$ & $\begin{array}{l}\text { 3. Carmen es a[w]ta y } \\
\text { de[w]gada }\end{array}$ & & $\begin{array}{l}\text { 4. Sofro muito com a sua } \\
\text { au[z]ência }\end{array}$ & $\begin{array}{l}\text { 5. [r]ápido se escribe con } \\
\text { la letra e[r]e }\end{array}$ & $\begin{array}{l}\text { 6. Faço aniversário em } \\
\text { abri[l] }\end{array}$ \\
\hline Informante 1 & & Explícito 3 & Explícito 3 & Explícito 2 & & Explícito 3 & Explícito 3 & Explícito 3 \\
\hline Informante 2 & & Explícito 3 & Explícito 3 & Explícito 3 & & Explícito 3 & Explícito 3 & Explícito 3 \\
\hline Informante 3 & & Explícito 3 & Explícito 2 & Explícito 1 & & Implícito & Explícito 3 & Explícito 3 \\
\hline Informante 4 & & Explícito 3 & Explícito 2 & Explícito 3 & & Explícito 3 & Explícito 3 & Explícito 3 \\
\hline Informante 5 & & Explícito 3 & Explícito 2 & Implícito & & Implícito & Implícito & Explícito 3 \\
\hline \multirow[t]{2}{*}{ Informante 6} & & Implícito & Implícito & Explícito 2 & & Explícito 3 & Explícito 3 & Explícito 3 \\
\hline & & & & $\begin{array}{l}\text { Total de Explícito 3: } \\
\text { Total de Explícito 2: } \\
\text { Total de Explícito 1: } \\
\text { Total de Implícito: }\end{array}$ & $\begin{array}{l}24 \\
5 \\
1 \\
6\end{array}$ & & & \\
\hline
\end{tabular}

Fonte: Silva (2014).

Quanto aos níveis mais baixos de consciência (implícito), é importante observar que nem sempre esses foram registrados nas mesmas frases em que os sujeitos haviam se equivocado no momento de julgar se essas estavam somente em português, somente em espanhol, ou, mescladas. Tais resultados permitem inferir que, por se tratar de diferentes tarefas e habilidades envolvidas, um mesmo sujeito pode não saber classificar corretamente uma determinada frase, porém, pode ser capaz de observar estruturas menores a ponto de explicitar, por exemplo, diferenças e semelhanças entre as mesmas.

Nos casos em que as respostas foram consideradas como nível implícito, observou-se a presença de outros aspectos que possam ter influenciando as respostas dos sujeitos, como, por exemplo, o foco na tradução ou no significado de uma palavra.

Na Tabela 5, adiante, são apresentados os níveis de consciência de sons atribuídos às respostas dadas pelo grupo de adultos.
De acordo com os dados descritos na Tabela 5, pode-se dizer que o grupo de adultos foi capaz de explicar corretamente 22 frases de um total de 36, sendo essas consideradas como nível Explícito 3. Dessas 22 frases, dezessete foram julgadas corretamente no reconhecimento das frases 1,3 , 5 e 6. Na sequência, tem-se cinco respostas condizentes ao explícito 2; uma resposta equivalente ao explícito 1 e, oito respostas pertencentes ao nível implícito.

É importante salientar que, embora os adultos tenham apresentado desempenhos relativamente maiores do que as crianças nos testes anteriores, durante a realização dessas entrevistas, observou-se melhor desenvoltura por parte das crianças. Em outras palavras, o grupo de crianças obteve um número maior de frases consideradas como nível explícito 3 (24), em comparação ao grupo de adultos (22). Além disso, destacam-se também o total de respostas classificadas como nível Implícito, sendo 
Tabela 5 - Nível de consciência de sons (explicação) - Grupo adultos

\begin{tabular}{|c|c|c|c|c|c|c|c|}
\hline Sujeitos & Frases & $\begin{array}{l}\text { 1. Pessoas dignas estão } \\
\text { cada vez mais [r]aras. }\end{array}$ & $\begin{array}{l}\text { 2. Mi ca[z]a es verde y } \\
\text { blanca. }\end{array}$ & $\begin{array}{l}\text { 3. Carmen es a[w]ta y } \\
\text { de[w]gada }\end{array}$ & $\begin{array}{l}\text { 4. Sofro muito com a sua } \\
\text { au[z]ência }\end{array}$ & $\begin{array}{l}\text { 5. [r]ápido se escribe con } \\
\text { la letra } \mathrm{e}[\mathrm{r}] \mathrm{e}\end{array}$ & $\begin{array}{l}\text { 6. Faço aniversário em } \\
\text { abri[l] }\end{array}$ \\
\hline Informante 7 & & Implícito & Implícito & Explícito 3 & Implícito & Explícito 2 & Explícito 3 \\
\hline Informante 8 & & Explícito 3 & Explícito 2 & Explícito 3 & Explícito 3 & Explícito 2 & Explícito 3 \\
\hline Informante 9 & & Explícito 3 & Explícito 3 & Explícito 1 & Implícito & Explícito 3 & Explícito 2 \\
\hline Informante 10 & & Explícito 3 & Explícito 3 & Explícito 3 & Explícito 2 & Explícito 3 & Explícito 3 \\
\hline Informante 11 & & Implícito & Explícito 3 & Explícito 3 & Implícito & Explícito 3 & Explícito 3 \\
\hline \multirow[t]{2}{*}{ Informante 12} & & Explícito 3 & Implícito & Implícito & Explícito 3 & Explícito 3 & Explícito 3 \\
\hline & & & & $\begin{array}{l}\text { Total de Explícito 3: } \\
\text { Total de Explícito 2: } \\
\text { Total de Explícito 1: } \\
\text { Total de Implícito: }\end{array}$ & $\begin{array}{c}22 \\
5 \\
1 \\
8\end{array}$ & & \\
\hline
\end{tabular}

Fonte: Silva (2014).

seis para as crianças, e oito para os adultos. Levando em consideração o número de respostas classificadas nesse nível, pode-se dizer que o grupo de crianças está mais próximo de apresentar respostas em níveis mais altos de consciência de sons.

Em suma, os resultados evidenciam que, de modo geral, crianças e adultos apresentam comportamentos semelhantes quando estão perante uma tarefa que lhes exija julgar sons e explicar o porquê de suas escolhas, inclusive, suas arguições foram bastante parecidas. Cabe destacar que os resultados encontrados nesse estudo podem variar consideravelmente de acordo com o público envolvido.

Quanto às maiores dificuldades dos participantes, observou-se que os mesmos costumam apresentar desempenhos mais baixos quando se trata de frases mescladas. Além disso, constatou-se que os referidos sujeitos podem apresentar diferentes desempenhos de acordo com o tipo de tarefa proposto. 0 informante 10, por exemplo, obteve médias de $87,3 \%$ de acertos no primeiro teste e, de 74,8\%, no segundo; já na entrevista, o mesmo sujeito julgou corretamente todas as frases e foi capaz de justificar conscientemente suas respostas, o que não pode ser observado nas demais tarefas.

\section{Considerações finais}

Enfim, procurou-se investigar se os participantes deste estudo seriam capazes de reconhecer diferenças entre os sons da língua espanhola e da língua portuguesa, especialmente, quando esses estivessem dispostos em um mesmo contexto frasal. Com base nas dificuldades verificadas em sala de aula e em diversos estudos, foram selecionados os pares de sons /s/ - /z/; /l/ - /w/ e /R/ - /r/ como foco deste trabalho. 
No que diz respeito aos referidos pares de sons, observou-se que, de modo geral, os informantes foram capazes de perceber mais facilmente as diferenças entre o par /R/ e / $\mathrm{r}$ / e demonstraram ter maior dificuldade para as diferenças entre o contraste /s/ e /z/. O par /l/ e /w/ foi considerado como intermediário, visto que em nenhum dos testes realizados o mesmo se mostrou tão significativo. Esses resultados não confirmaram as hipóteses deste estudo, visto que se esperava que os sujeitos percebessem mais facilmente o par /s/ e /z/, pelo fato de o segundo som não existir em espanhol (o que permitiria generalizações), e que o par /r/ e /R/ envolvesse mais dificuldade pelo fato desses sons existirem em ambas as línguas e apresentarem diferentes possibilidades alofônicas, o que não se confirmou.

Com vistas a observar se o tipo de instrumento (teste 1 e 2), o grupo (crianças e adultos) e o nível de conhecimento na língua-alvo (básico ou pré-intermediário) poderiam influenciar no desempenho dos participantes desse estudo, realizaram-se vários testes de diferença e averiguou-se que essas variáveis não foram significativas para o desempenho desses sujeitos. Embora as médias dos adultos tenham sido, em geral, superiores às médias alcançadas pelas crianças, não se observa uma diferença estatisticamente entre esses grupos. Com relação ao tipo instrumento, tampouco foram identificadas diferenças significativas. Quanto à entrevista, por meio de uma análise qualitativa, constatou-se que os informantes podem apresentar diferentes desempenhos de acordo com o tipo de tarefa proposto.

Em suma, esta pesquisa procurou mostrar a importância de se desenvolverem estudos que abarquem níveis de consciência fonológica e de representação mental intrinsicamente ligados ao processo de aprendizagem de espanhol como LE - área em que os estudos ainda são escassos. Pretendeu-se, enfim, mostrar que o trabalho com a consciência fonológica não deve se perder ao longo da aquisição da leitura e da escrita, muito pelo contrário, torna-se necessário a realização de estudos também com sujeitos já alfabetizados. Além disso, espera-se poder contribuir com a prática docente do professor de LE, para que seu trabalho seja facilitado, possibilitando-lhe a obtenção de melhores resultados em sala de aula e, aos aprendizes, maiores possibilidades de aprendizagem. Para finalizar, é importante destacar a necessidade de serem realizadas pesquisas semelhantes a essa, envolvendo o estudo de outras línguas, de outros sujeitos, de outros espaços de ensino e de aprendizagem.

\section{Referências}

ALVES, U. K. O papel da instrução explícita na aquisição fonológica do inglês como L2: evidências fornecidas pela Teoria da Otimidade. Dissertação (Mestrado) - Universidade Católica de Pelotas, Pelotas, 2004.

O que é consciência fonológica. In: LAMPRECHT, R. (Org.). Consciência dos sons da língua. Porto Alegre: EDIPUCRS, 2009.

AQUINO, A; ZIMMER, M. C. Consciência Fonológica em inglês (L2) e a percepção da sílaba. In: IV SENALE, 2005. Pelotas: UCPEL, 2005.

BATTISTELLA, T. R. A relação entre a percepção, a produção e consciência fonológica na aprendizagem do inglês como língua estrangeira. Dissertação (Mestrado) - Pontifícia Universidade Católica do Rio Grande do Sul, Porto Alegre, 2010.

BISOL, L. Introdução a estudos de fonologia do português brasileiro. Porto Alegre: EDIPUCRS, 2010.

BLANCO-DUTRA, A. P. Instrumentos de avaliação de consciência fonológica. In: LAMPRECHT, R. R. (Org.). Consciência dos sons da língua. Porto Alegre: EDIPUCRS, 2009.

CARDOSO-MARTINS, C. Consciência fonológica e alfabetização. Petrópolis: Vozes, 1995.

COSTA, R. S. A produção da lateral /l/ por alunos de espanhol/LE da Universidade Estadual do Ceará. Dissertação (Mestrado) - Universidade do Estado do Ceará, Fortaleza, 2013.

CRISTÓFARO-SILVA, T. Pronúncia do Inglês para falantes nativos do português brasileiro: os sons. Belo Horizonte: FALE/UFMG, 2005. 
FERNÁNDEZ, A. L. R. N. Interface português/espanhol: o problema de fonemas em uma língua e alofonia em outra. Dissertação (Mestrado) - Universidade Católica de Pelotas, Pelotas, 2001.

FLEGE, J. E. Second language speech learning: theory, findings and problems. In: STRAN $\neg \mathrm{GE}, \mathrm{W}$. (Ed.). Speech perception and linguistic experience: issues in cross-language research. Timonium, MD: York Press, 1995. p. 233-277.

FREITAS, G. C. M. de. Consciência fonológica: rimas e aliterações no português brasileiro. Letras de Hoje, v. 38, n. 2, p. 155-170, 2003.

FREITAS, G. C. M. de. Sobre a consciência fonológica. In: LAMPRECHT, R. Aquisição Fonológica do Português: Perfil de desenvolvimento e subsídios para a terapia. Porto Alegre: Artmed, 2004. p. 177-192.

GOMES, A. S. A vibrante múltipla espanhola em aprendentes de espanhol como língua estrangeira na Bahia e em São Paulo: uma abordagem sociolinguística. 124f. 2013. Dissertação (Mestrado) - Universidade do Estado da Bahia (UNEB), Salvador, 2013.

HARRIS, J. W. Syllabe structure and stress in Spanish: a nonlinear analysis. Cambridge (MAS): The MIT Press. 1983.

KARMILOFF-SMITH, A. From meta-processes to conscious access: Evidence from children"s metalinguistic and repair data. Cognition, v. 23, p. 95-147, 1986.

Beyond Modularity: a developmental perspective on cognitive science. Cambridge (MAS): MIT, 1992.

LADEFOGED, Peter. A course in Phonetics. New York: Harcourt, Brace \& Jovanovich, 1975. LEFFA, V. J. Uma ferramenta de autoria para o professor: o que é e o que faz. Letras de Hoje, v. 41, n. 2, p. 189-214, 2006.

LEMLE, M. Guia teórico do alfabetizador. São Paulo: Ática, 2003.

LORANDI, A. A consciência linguística e o modelo de Redescrição Representacional: como explicar a discrepância entre os processos de consciência em diferentes microdomínios? In: FERREIRA GONÇALVES, G.; BRUM DE PAULA, M. R.; KESKE-SOARES, M. (Org.). Estudos em Aquisição Fonológica. Pelotas: UFPel, 2011.

LORANDI, A.; KARMILOFF-SMITH, A. From sensitivity to awareness: the morphological knowledge and the Representational Redescription Model. Letras de Hoje, Porto Alegre, v. 47, n. 1, p. 6-16, 2012.

MATTOSO CÂMARA JR, J. M. Estrutura da língua portuguesa. Petrópolis: Vozes, 1984.
MIRANDA, A. R. M. A representação das consoantes róticas nos sistemas de crianças brasileiras e argentinas. Letras de Hoje, Porto Alegre, v. 8, n. 2, p. 111-122, 2001.

MORAIS, J. A arte de ler. São Paulo: Editora da Universidade Estadual Paulista, 1996.

NESDALE, A. R.; TUNMER, W. E. The development of metalinguistic awareness: methodological overview. In: TUNMER, W. E.; PRATT, C.; HERRIMAN, M. L. (Ed.) Metalinguistic awareness in children: theory, research and implications. Berlim: SpringerVerlag, 1984. p. 36-55. https://doi.org/10.1007/978-3-642-69113-3_3

ROAZZI, A.; DOWKER, A. Consciência fonológica: rima e aprendizagem da leitura Psicologia: Teoria e Pesquisa, Brasília, v. 5, n. 1, p. 31-55, 1989.

RUEDA, M. La lectura - Adquisición, dificultades e intervención. Salamanca: Amarú Ediciones, 1995.

SCHERER, A. P. R. Conversa inicial. In. LAMPRECHT, R. R. (Org.). Consciência dos sons da língua. Porto Alegre: EDIPUCRS, 2009.

SCLIAR-CABRAL, L. Capacidades metafonológicas e os princípios do sistema alfabético do português do Brasil. In: VI CONGRESSO BRASILEIRO DE NEUROPSICOLOGIA: Rio de Janeiro, 1999.

SILVA, F. S. Consciência fonológica em língua estrangeira: um estudo acerca da aquisição de espanhol por falantes brasileiros. Dissertação (Mestrado) - Universidade Católica de Pelotas, Pelotas, 2014.

SILVEIRA, R.; SOUZA, T. T. A percepção e a produção das fricativas alveolares da língua portuguesa por hispano-falantes. Rev. Est. Ling., Belo Horizonte, v. 19, n. 2, p. 167-184, 2011 ,

TUNMER, W. E.; HERRIMAN, M. L. The development of metalinguistic awareness: conceptual overview. In: TUNMER, W. E.; PRATT, C.; HERRIMAN, M. L. (Ed.). Metalinguistic awareness in children: theory, research and implications. Berlim: Springer-Verlag, 1984. p. 12-35. https://doi.org/10.1007/978-3-642-69113-3_2

ZIMMER, M. C. Cognição e aprendizagem de L2: uma abordagem conexionista. In: FELTES, H.; FARIAS, E. M. P.; MACEDO, A. C. P. (Org.). Cognição e linguística. Caxias do Sul: EDUSC, 2008.

Recebido em 25/01/2017. Aceito em 16/06/2017. 